\title{
Power, Ideology, and Technological Determinism
}

A Commentary on Taylor Dotson's “Technological Determinism and Permissionless Innovation as Technocratic Governing Mentalities: Psychocultural Barriers to the Democratization of Technology"

\author{
DAVID J. HESS \\ Vanderbilt University
}

\section{Keywords}

permissionless innovation; technological determinism; STS; political sociology; social science methodology

Central to popular understandings of the politics of technology, the idea of technological determinism has also been the topic of a scholarly literature. Leo Marx and Merritt Roe Smith define it as the idea that "an invention, once introduced into society," takes on "a life of its own" (1994: xi), and Langdon Winner argues that the core assumption of technological determinism is that technology forms the basis of social life and that "changes in technology are the single most important basis of change in society" (1977: 65). Smith and Marx argue that this view circulates widely in the media, and Winner notes that some scholars also embrace it (e.g., White 1949).

Two main problems plague some scholarly uses of the concept of technological determinism: they can provide a unicausal explanation of historical change rather than attending to the complex interaction of causal factors, and they treat technology as an exogenous variable instead of examining how society also affects technological trajectories. Winner recognizes these methodological problems, but he also argues that one should "avoid throwing out the baby with the methodological bath water" (1977: 77). Like Marx and Smith, he argues that there is a need for sound research that takes seriously the idea that technological change has important social effects but does not fall prey to the methodological shortcomings of unicausal, exogenous explanations. An important strategy for understanding both the power of technology in society and for avoiding simplistic formulations of its social effects is to examine the conditions for the failure and success of efforts to develop a vigorous democratic politics of technology. As I will argue,

. David J. Hess, Email: david.j.hess@Vanderbilt

Copyright (C) 2015 (David J. Hess). Licensed under the Creative Commons Attribution Non-commercial No Derivatives (by-nc-nd). Available at estsjournal.org. 
undertaking this empirical research project requires careful attention to methodology and theoretical frameworks.

Winner suggests that one factor impeding the project of developing a democratic politics of technology is "technological somnambulism," in which "we so willingly sleepwalk through the process of reconstituting the conditions of everyday life" (1986: 10). In other words, technology becomes so embedded in our everyday lives that we do not think about it from a political perspective except to regulate it when evidence of its risks or misuse becomes obvious. In contrast, a vigorous democratic politics of technology requires analyzing the social conditions of innovation and developing grassroots experimentation with politically inspired alternative designs. In turn, the latter requires going beyond the idea that technology requires more legislation (i.e., regulation) and instead building on the idea that technology is legislation (1977: 323). One source of such politics is in the technology-oriented social movements that seek not only the sunsetting of undesirable technologies and infrastructures (such as carbon-intensive energy and industrialized agriculture) but also their replacement with alternative technologies associated with grassroots innovation (Hess 2007).

Working in this tradition, Dotson (2015) suggests an approach to examining the barriers that make the democratic politics of technology difficult to achieve: the governing mentalities that serve as psychocultural barriers to the critical analysis of technological determinism and somnambulism. Although I am in general agreement with the idea of developing a social theory of the conditions of success and failure for a democratic politics of technology, I think it is necessary to think carefully about the choice of theoretical frameworks and problems of methodology.

First, the goal of explaining the barriers to a democratic politics of technology requires a theoretical framework that is not restricted to the unicausal method of semiotic or psychocultural analysis. A more holistic and effective theoretical framework draws on the social theory triangle of meaning, agency, and structure, which is well recognized in the relevant fields of political science as the three I's (ideas, interests, and institutions) and of political sociology as the role of frames and culture, mobilizing structures, and opportunity structures (Rootes et al. 2012, McAdam et al. 2001). Environmental conditions can also be included, although they are always interpreted and can be modified by social action. Field theory is an example of a framework that brings together these perspectives in a unified whole, and there are various projects underway in STS that experiment with field theoretical approaches (Albert and Kleinman 2011, Frickel and Hess 2014). Importantly, field theory draws attention to pervasive inequality in society based on general disparities in capacity to influence outcomes, such as political and technological change, due to the interaction of field position with the broader dimensions of structural inequality such as class, race, gender, and global position. Field theory takes into account these structural factors while providing a more comprehensive approach to the analysis of barriers to a democratic politics of technology than does a restricted focus on mentalities and meanings. The analysis of meanings is recognized as important, but it is embedded in a broader framework that includes structural inequality, strategies of actors, and relations within and among social fields. In 
Bourdieu's terms, the approach goes beyond the "attempts to understand the field of stances in itself and for itself, that is, independent of the field of positions" (1991: 11).

The concept of "permissionless innovation" (Dotson 2015) can be used to provide an example of the advantages of this more holistic approach. As a catch-phrase that legitimates the need for technology companies to be liberated from needless regulatory restrictions, it is more than a sui generis or exogenous cultural mentality. It is also part of the broader neoliberal ideology that is itself socially produced through mobilizations of actors who have powerful positions in the social structure and in the political and industrial fields. Such expressions of neoliberal thought have currency in the media and in the political field because of the concerted efforts of large corporations and conservative donors to break down the formerly consensual ideology of progressive liberalism, which advocated for a stronger role for the state in guiding the economy. In the U.S. the conservative mobilization resulted in the corralling of the government with a series of new organizations and reinvigorated older organizations, such as think tanks and public relations firms, as well as control of important media outlets and the purging of moderate candidates from the Republican Party, all of which shifted political discourse toward neoliberalism (Barley 2010). Thus, a complete analysis of the conditions of failure of a democratic politics of technology needs to examine the causal sequences that lead to changes in both social positions and positions on issues (or stances) in the relevant social fields.

The second qualification involves the related attempt to analyze the strategies to overcome barriers to a democratic politics of technology. Certainly, the role of having appropriate framing of messages is important and widely recognized in STS work on efforts to build a democratic politics of science and technology (e.g., Frickel 2004, Lubitow 2013). For example, in our analysis of the politics of sustainability transitions, my students and I have examined how frames can be aligned with conservative ideology to overcome political opposition to renewable energy and energy efficiency legislation (e.g., Hess et al. 2016). However, the focus only on frames or other expressions of meaning can lead to a restricted analysis of the strategies for overcoming the problem. Instead, one must again draw on a more holistic analytical framework to direct attention to the role of effective mobilization and to strategies for opening a closed political and industrial opportunity structure.

To provide another example, the problem of overcoming barriers to a blocked political and industrial opportunity structure is particularly acute in the case of steering industrial transitions to more sustainable technological systems. In addition to the analysis of the semiotic dimension, research needs to focus on the successful and unsuccessful strategies of social movements that seek to open a blocked political and industrial opportunity structure (Hess 2007). But even the analysis of social movements per se is inadequate because in many examples of political conflict over sustainability transitions the social movements lack the resources to affect change in a political field that is heavily dominated by the interests of industrial regime organizations such as fossil-fuel companies. Hence, coalitions with countervailing political power such as the small business sector (Hess 2009), the labor movement (Hess 2012), and the technology sector (Hess 2014) are necessary in order to mount more effective challenges. Furthermore, closer to Winner's vision of a democratic politics of technology that is not restricted 
to policy guidance and legislative reform, social movements can also provide opportunities for developing alternative innovations and designs, such as approaches to urban design that simultaneously address resilience and sustainability goals or health and sustainability goals (Hess 2013).

The structure-agency-meaning triangle is necessary to broaden the study not only of the causes of the barriers but also of the strategies for overcoming them. Doing so also allows researchers to ponder broader issues such as the best state-market relationship for enabling a democratic politics of technology. Evans's (1995) condition of embedded autonomy for the state-where the government has autonomy from industrial rent-seeking but a good understanding of and communication with industry-points to one possible precondition for successful industrial policies that could proactively steer industrial transitions. However, in contrast to the successful developmentalist states that he studied, in the U.S. the autonomy of the political field has been deeply compromised. The broken system of campaign finance has led to the double-election process: the money election, where candidates must gain the support of wealthy donors, and the general election, where they must win the support of the voters with the help of their supporters from the money election (Lessig 2013). In addition to the analysis of the effects of campaign finance reform and other policies that would enhance the autonomy of the political field, it would be good to have analyses of other approaches that attend to even deeper issues of structural inequality, such as the effectiveness of the municipalization or the nationalization of firms that are blocking transitions.

In summary, it is valuable to attend to the role of frames, cultural meanings, semiotic structures, imaginaries, and governing mentalities in the analysis of the conditions that can explain the construction of a robust democratic politics of technology. However, a methodology restricted to this approach, or "culturalism," can result in "theory somnambulism" that is akin to the technological somnambulism that Winner described. The otherwise insightful analyses that cultural methods, like Dotson's, produce could be much more robust if situated in a broader framework that attends to the interactions of meanings, structures, and agencies. This approach can point to the role of social movements, coalitions with countervailing powers, and creative patterns of design and innovation that address more than one political constituency and goal. The holistic approach can also help to connect a normative philosophy of democracy and technology with the insights of explanatory social science.

\section{References}

Albert, M. and D. L. Kleinman. 2011. Bringing Pierre Bourdieu to Science and Technology Studies. Minerva 49(3): 263-273.

Barley, S. 2010. "Building an Institutional Field to Corral a Government: A Case to Set an Agenda for Organization Studies." Organizational Studies 31(6): 777-805.

Bourdieu, P. 1991. “The History of Scientific Reason." Sociological Forum 6(1): 3-26. 
Dotson, T. 2015. “Technological Determinism and Permissionless Innovation as Technocratic Governing Mentalities: Psychocultural Barriers to the Democratization of Technology." Engaging Science, Technology, and Society 1: 98-120. DOI: http://dx.doi.org/10.17351/ests2015.009.

Evans, P. 1995. Embedded Autonomy: States and Industrial Transformation. Princeton, N.J.: Princeton University Press.

Frickel, S. 2004. Chemical Consequences: Environmental Mutagens, Scientist Activism and the Rise of Genetic Toxicology. New Brunswick, NJ: Rutgers University Press.

Frickel, S. and D. J. Hess. 2014. "Fields of Knowledge: Science, Politics, and Publics in the Neoliberal Age." Special issue of Political Power and Social Theory 27: 1-289.

Hess, D. J. 2007. Alternative Pathways in Science and Industry: Activism, Innovation, and the Environment in an Era of Globalization. Cambridge, MA: MIT Press. 2009. Localist Movements in a Global Economy. MIT Press. . 2012. Good Green Jobs in a Global Economy. MIT Press.

. 2013. "Transitions in Energy Systems: The Mitigation-Adaptation Relationship." Science as Culture, special issue on energy futures. 22(2): 197-203.

. 2014. "Sustainability Transitions: A Political Coalition Perspective." Research Policy 43(2): 278-283.

Hess, D. J., Q. D. Mai, and K. P. Brown. 2016. “Red States, Green Laws: Ideology and Renewable Energy Legislation in the United States." Energy Research and Social Science.

Lessig, L. 2013. "We the People, and the Republic We Must Reclaim." https:/ / www.ted.com/talks/lawrence_lessig_we_the_people_and_the_republic_we_mu st_reclaim/transcript?language $=$ en .

Lubitow, A. 2013. "Collaborative Frame Construction in Social Movement Campaigns: Bisphenol-A and Scientist-activist Mobilizations." Social Movement Studies 12(4): 429-44.

Marx, L. and M. R. Smith. 1994. "Introduction." In Merritt Roe Smith and Leo Marx (eds.), Does Technology Drive History? The Dilemma of Technological Determinism. Cambridge, MA: MIT Press. Pp. ix-xv.

McAdam, D., S. Tarrow, and C. Tilley. 2001. Dynamics of Contention. Cambridge, U.K.: Cambridge University Press.

Rootes, C., Z., Anthony, and J. Barry. 2012. Climate change, national politics, and grassroots action: an introduction. Environmental Politics 21(5): 677-690.

White, L. 1949. The Science of Culture. New York: Farrar, Strauss, and Giroux.

Winner, L. 1977. Autonomous Technology. Cambridge, MA: MIT Press. . 1986. The Whale and the Reactor. Chicago: University of Chicago Press. 